\title{
The Center for Environmental Technology Innovative Technology Screening Process
}

\section{C.M. Bertrand}

Date Issued-February 1995

\author{
Prepared by \\ Health Sciences Research Division \\ Oak Ridge National Laboratory \\ Oak Ridge, Tennessee
}

Prepared for

Center for Environmental Technology

Oak Ridge, Tennessee

\section{OAK RIDGE NATIONAL LABORATORY}

Oak Ridge, Tennessee 37831-6285 managed by

MARTIN MARIETTA ENERGY SYSTEMS, INC. for the

U.S. DEPARTMENT OF ENERGY under contract DE-AC05-84OR21400

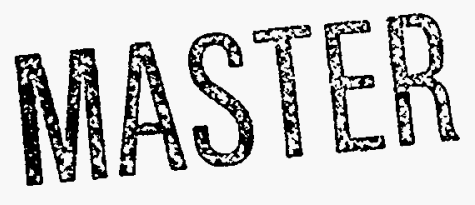




\section{CONTENTS}

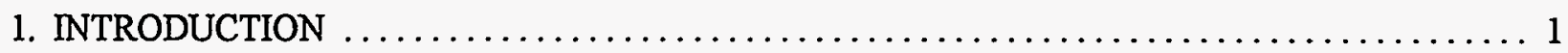

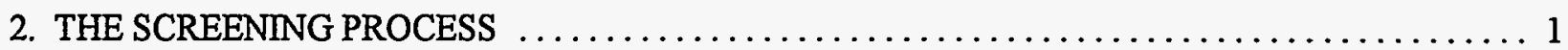

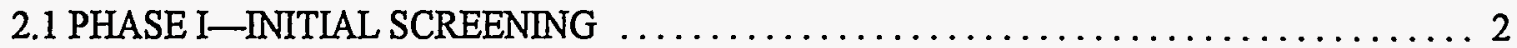

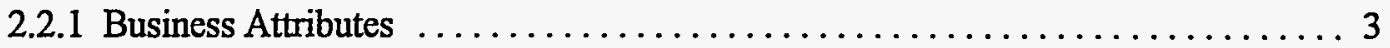

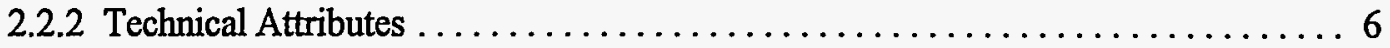

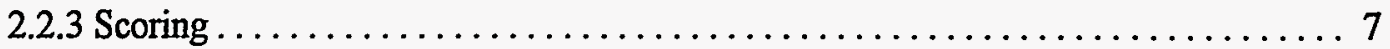

2.3 PHASE III-INTENSIVE TECHNOLOGY REVIEW $\ldots \ldots \ldots \ldots \ldots \ldots \ldots \ldots \ldots 8$

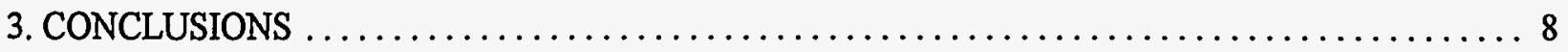

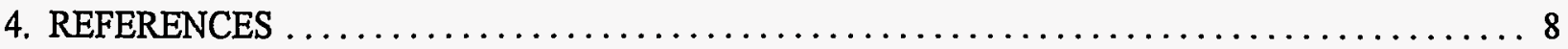

DISCLAIMER

This report was prepared as an account of work sponsored by an agency of the United States Government. Neither the United States Government nor any agency thereof, nor any of their employees, makes any warranty, express or implied, or assumes any legal liability or responsibility for the accuracy, completeness, or usefulness of any information, apparatus, product, or process disclosed, or represents that its use would not infringe privately owned rights. Reference herein to any specific commercial product, process, or service by trade name, trademark, manufacturer, or otherwise does not necessarily constitute or imply its endorsement, recommendation, or favoring by the United States Government or any agency thereof. The views and opinions of authors expressed herein do not necessarily state or reflect those of the United States Government or any agency thereof. 


\section{DISCLAIMER}

Portions of this document may be illegible in electronic image products. Images are produced from the best available original document. 


\section{INTRODUCTION}

The Center for Environmental Technology's (CET) mission is to provide a fully integrated system for accelerated evaluation, development, commercialization, and public acceptance of creative environmental solutions which match the foremost demands in today's environmentally sensitive world. In short, CET will create a means to provide quick, effective solutions for environmental needs. To meet this mission objective, CET has created a unique and innovative approach to eliminating the usual barriers in developing and testing environmental technologies. The approach paves the way for these emerging, cutting-edge technologies by coordinating environmental restoration and waste management activities of industry, universities, and the government to:

- $\quad$ efficiently and effectively transfer technology to these users,

- provide market-driven, cost-effective technology programs to the public and DOE, and

- aid in developing innovative ideas by initiating engineering efforts between DOE facilities and private industry.

The central part to this mission is selecting and evaluating specific innovative technologies for demonstration and application at United States Department of Energy (DOE) installations. The methodology and criteria used for this selection, which is called the CET Innovative Technology Screening Process, is the subject of this paper.

The developed process is a phased-approach methodology designed to pinpoint technologies that demonstrate the greatest potential for improving human health and the environment. The selection criteria used for the screening process were modeled after other DOE technology transfer programs and were further developed by CET's Technology Screening and Evaluation Board (TSEB). The process benefits both CET and the proposing vendors by providing objective selection procedures based on predefined criteria. The selection process ensures a rapid response to proposing vendors, all technologies will have the opportunity to enter the selection process, and all technologies are evaluated on the same scale and with identical criteria. Appendix A contains a flow chart which specifically outlines the process CET has established.

\section{THE SCREENING PROCESS}

The screening process is the most critical aspect of CET's technology transfer mission, and it is essential that the process be accurate and objective and select technologies with the most technical and business promise. To facilitate this need, a three-phase approach was developed to review the technologies on an increasingly stringent scale:

- Phase I: Initial Screening

- Phase II: $\quad$ Business/Technical Review

- Phase III: Detailed Analysis

The TSEB was established to support these goals in the selection process and be responsible for the actual technical review and technology selection processes conducted in Phases II and III. The TSEB 
comprises science and engineering experts, federal regulators, state regulators, and CET senior management. The board members review all the proposed technologies that are presented to the Center.

\subsection{PHASE I-INITIAL SCREENING}

Phase I is not intended to be a technical review or elimination process, rather it is an administrative formality and information gathering procedure. The initial screening process consists of a review of material submitted on the proposed technology by the CET administrative personnel to determine if an unsolicited proposal has been received. In addition, the screening process ensures that the technology information is presented in CET's standard proposal format (Appendix B). Vendors who want to demonstrate their technology are required to submit a proposal to CET in this standardized format, which requires the vendor to briefly describe certain aspects about the technology. Information provided in this proposal will supply TSEB with enough material to conduct a complete technology evaluation. By setting the size and information parameters as outlined in the standardized proposal format, each proposal is uniform and can be objectively reviewed.

Once a completed proposal is received, a response recognizing its receipt is forwarded to the vendor within one week. This response includes a description of the CET innovative technology screening process and a listing of the criteria the technologies are reviewed against in each phase. A database is being developed so that associated vendor and technology information can be tracked through the selection process. The database will also allow CET to remain in contact with these vendors for any future opportunities and quickly reference information such as the number of technologies entered in the system for a particular contaminant and media, other technologies that perform similar functions to the one being proposed, and the number of technologies submitted to CET by a particular vendor.

Upon completion of Phase $\mathrm{I}$, a technology package with all required information is forwarded to the TSEB for scoring. At this time, vendors are notified that their technology package is complete and has moved into the Phase II evaluation process.

\subsection{PHASE II-BUSINESS/TECHNICAL REVIEW}

The business/technical evaluation of the proposed innovative technology is conducted by the CET TSEB during Phase II of the screening process. The Phase II evaluation is grouped according to specific criteria which are weighted based upon each criterion's importance to CET's overall mission. The criteria are divided into two technology attribute categories: business attributes and technical attributes. The technical attributes determine the scientific and engineering feasibility of the proposed technology, while the business attributes determine the commercialization likelihood of the technology. The following list presents the business and technical attributes.

\section{BUSINESS ATTRIBUTES}

1. Cost sharing

2. Time to Commercialization

3. Demonstration Duration

4. Probable Cost Advantage

5. Market Breadth 
6. Regulatory Acceptability

7. Public Perception

\section{TECHNICAL ATTRIBUTES}

1. Technical Feasibility

2. Technical Compatibility

3. Complexity

4. Process Advantage

5. Developmental Maturity

6. DOE Technology Needs

Figure 1 presents a score sheet including the attributes and factor involved in the selection process. The following subsections discuss the business and technical attributes in further detail and includes pertinent questions that must be addressed for each attribute.

\subsubsection{Business Attributes}

\section{Cost Sharing}

- Of the total cost, what percentage will the proposing vendor be able to fund?

Vendors financially willing to support their technologies for a demonstration will have a greater likelihood of being selected than those that will require complete DOE funding. Scoring of this attribute is based on a range of percentages of the cost the company can provide (refer to Fig. 1):

$\square 0-24 \% \square 25-49 \% \square 50-74 \% \square 75-99 \% \square 100 \%$

The numerical scoring scale ranges from 0 to 10 . Therefore, a hypothetical vendor providing between only 0 and $24 \%$ of the demonstration cost is assigned a score of 2 for the Cost Sharing attribute.

\section{Time to Commercialization}

- What is the estimated time frame to develop a product that can be commercialized?

Technologies requiring extended time periods for commercialization are also a financial burden. Technologies CET will be able to rapidly commercialize will score higher than those for which commercialization will take several years.

\section{Demonstration Duration}

- What is the time commitment for the demonstration?

The same significance for a short time frame as discussed previously applies to the demonstration 


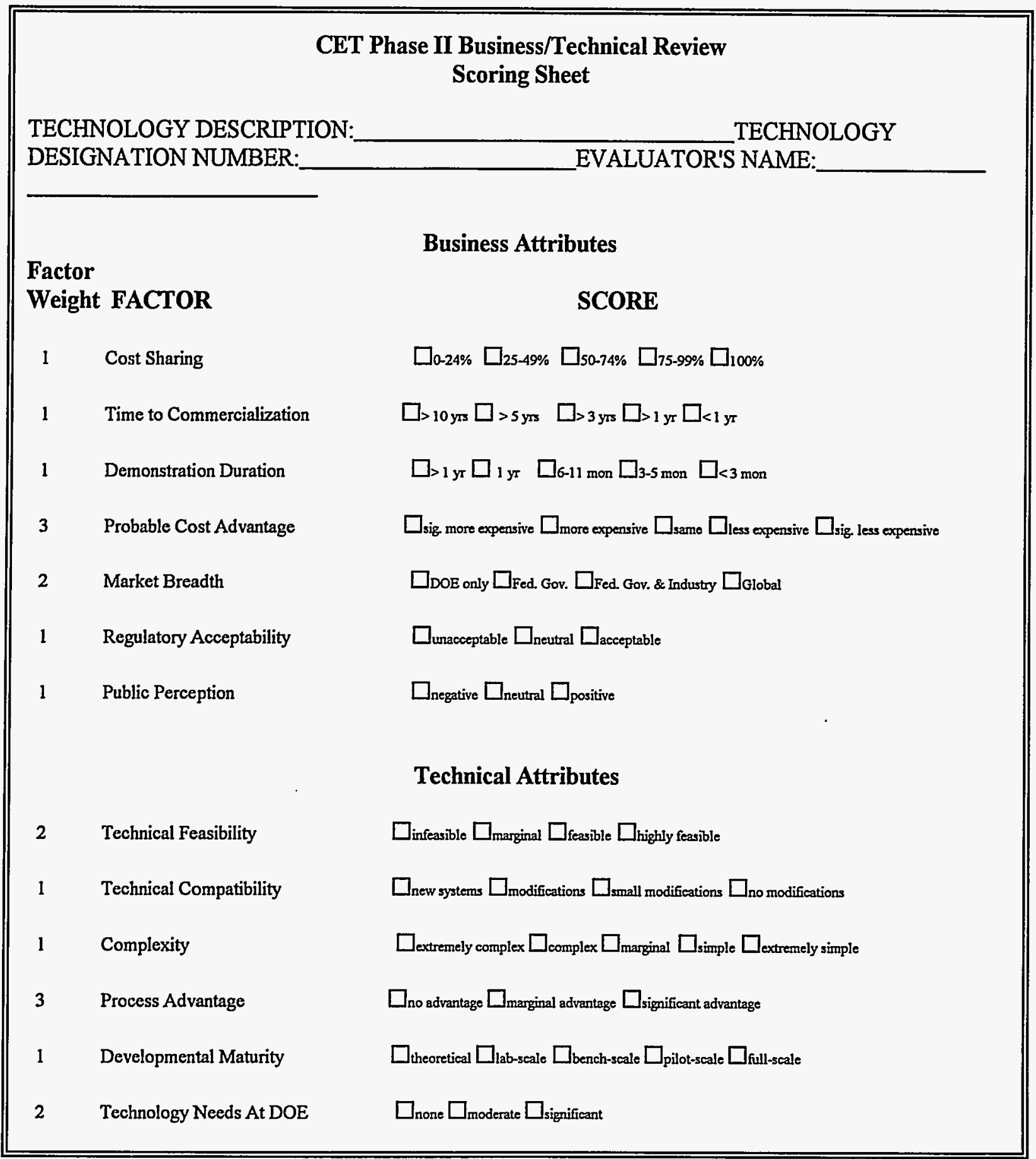

Fig. 1. Example Score Sheet for Business and Technical Attributes. 
duration. Long demonstrations will not only increase the time to make the technology available on the market but will be more expensive. The scaling for the demonstration duration ranges from less than 3 months to more than one year.

\section{Probable Cost Advantage}

- Does the product require lower capital investment and/or operation and maintenance costs than competing technologies?

Although the technical capabilities of an innovative technology may be equivalent to that of a competing technology, the comparative cost savings could be significant. This attribute is not to be evaluated on "technical process" savings, such as disposal cost saved in reducing wastes, but on business savings such as initial capital investment and operation and maintenance costs. The scale associated with this attribute is divided into five categories (refer to Fig. 1):

$\square$ sig. more expensive $\square$ more expensive $\square$ same $\square$ less expensive $\square$ sig. less expensive

A majority of the responses should fall between the categories more expensive, same, and less expensive. The actual cost of a project is hard to determine and will require each TSEB member's best estimate. The ranges defined as "significant" are reserved for those cases where the cost of the technology is obviously a substantial savings or burden.

\section{Market Breadth}

- In how many markets could the technology be used and commercialized?

Technologies that are specific only to a particular site or DOE facility do not have tremendous commercialization potential. The CET's mission is to aid in developing technologies that will have a tremendous impact in the environmental arena. The score for this attribute is directly related the size of the market.

\section{Regulatory Acceptability}

- What would be the regulator's perception of the new technology?

This criterion is divided into three scoring levels: unacceptable, neutral, and positive. Judgement is made based on the opinions of the experts and their regulatory knowledge and past experiences. A more specific evaluation of compliance issues is conducted during Phase III. The logic behind the scoring is if commercialization of the technology requires CET to enter into negotiations with the regulators, the time involved in the process will be lengthy thereby adding to the time to commercialization. Evaluators are instructed that if regulations do not apply to the technology, a score of "positive" should be applied.

\section{Public Perception}

- What would be the public's perception of the new technology?

This is a judgement on how the public and/or potential user would react to the technology. Is the innovative part of the technology apparent so that the public/user will be interested in its commercialization, 
or does it have an aspect that will give a negative perception of the product?

\subsubsection{Technical Attributes}

\section{Technical Feasibility}

- Will the technology work?

The actual science/engineering principles on which the technology is designed are evaluated by the TSEB members and then assigned a score. All aspects associated with the vendor's claims of the technology's abilities are reviewed for validity under this attribute.

\section{Technical Compatibility}

- Can the process be easily introduced into existing systems that are expected to use it in some manner?

- Would the process require the purchase of new expensive supporting equipment?

Although a technology is feasible and has an obvious vast process advantage, the system may require investment in new equipment to become operational. Those technologies not requiring equipment/system modifications are given high scores generally, while those requiring new systems are scored low.

\section{Complexity}

- Does the technology require equipment or parts that are susceptible to damage?

- Will manufacture require special tools, dies, or machines that are difficult to obtain or expensive?

- Will personnel training be involved and highly technical?

As stated previously, complex technologies can be a tremendous expense to the user. Unless the technology has a distinctive process advantage, potential users will fail to see the superiority of the technology. Personnel changes, operation and maintenance costs, and other expenses will drive down the commercial potential of the technology.

\section{Process Advantage}

- Does the process provide an advantage (i.e., solve a problem) over a competing technology/product?

- Does the technology produce better quality, less wastes, and/or lower pollutants?

The key phrase to answering these questions is determining if the technology is "faster, cheaper, or better." This attribute is weighted heavily against the others because it represents CET's mission to encourage the design of innovative technologies. The greater the advantage this technology has as compared to competitive technologies, the greater the likelihood it will be selected for demonstration. 


\section{Developmental Maturity}

- At what stage is the technology in the development process?

Certain risks are associated with the scale-up of technologies. A technology in the theoretical stage may not actually be able to reach a field-ready design. If funding is allocated towards the development of a technology requiring scale-up and a design flaw is discovered in the full-scale model, CET potentially could suffer tremendous financial losses. If the technology is close to actual field implementation, then fewer risks will be involved in discovering design flaws and other obstacles.

\section{DOE Technology Needs}

- Is the technology needed within the DOE complex?

The technology demonstrations will be conducted on DOE facilities. Sites for the demonstration must be available for the technology to be considered. It is important to note that this is not a review associated with a specific site, but a general overview of the types and numbers of sites across the DOE Complex where the technology could be useful.

\subsubsection{Scoring}

After all the questions have been answered for each attribute and a score has been give, the scores will be calculated by summing the business attributes and the technical attributes as follows:

$$
\text { Score }_{B}=\sum\left(b_{i}\right)\left(s_{i}\right)
$$

where

$$
\begin{array}{lll}
\text { Score }_{\mathrm{B}} & = & \text { The summation of the business attributes } \\
\mathrm{b}_{\mathrm{i}} & = & \text { The factor weight of the attribute (Fig. 1) } \\
\mathrm{s}_{\mathrm{i}} & = & \text { The assigned score from the evaluator }
\end{array}
$$

$$
\text { Score }_{\mathrm{T}}=\sum\left(\mathrm{b}_{\mathrm{i}}\right)\left(\mathrm{s}_{\mathrm{i}}\right)
$$

where

$$
\begin{array}{lll}
\text { Score }_{\mathrm{T}} & = & \text { The summation of the technical attributes } \\
\mathrm{b}_{\mathrm{i}} & = & \text { The factor weight of the attribute (Fig. 1) } \\
\mathrm{s}_{\mathrm{i}} & = & \text { The assigned score from the evaluator }
\end{array}
$$

The proposed technologies will be ranked for both attributes according to their score and by the mean of the business and technical score. The TSEB members will be provided a copy of the scoring sheet by electronic mail and requested to submit the evaluation results back to CET within two weeks of receiving the technology information package. The TSEB members also will be requested to attend monthly meetings where technologies selected during the Phase II screening will be discussed. 


\subsection{PHASE III-INTENSIVE TECHNOLOGY REVIEW}

Technologies selected for further evaluation during the Phase II review undergo an intense technical screening process with the Phase III selection. Vendors will be invited to CET to present the technology and answer reviewer questions. The reviewers will evaluate the technology in this final phase according to the following criteria:

- What are the limitations of the technology?

- What data exist to substantiate vendor claims? What other information is needed to prove the technology will work?

- Does implementation of the technology fit in with CET's budget plans?

- Is the technology acceptable to the federal/state/local regulators?

- Can both long- and short-term benefits be derived from this technology?

- Is there a compatible site willing to allow a technology demonstration?

At this point, vendors will be notified if their submitted technology was selected for the possibility of a demonstration during the Phase III selection process.

\section{CONCLUSIONS}

At the end of the three-phase screening process, innovative technologies that have been selected will be entered into a comprehensive business planning phase. Since demonstrations are financed on a limited budget, each technology must be scheduled for a demonstration when funding support is available. Although a technology has passed screening, CET can decide the technology will not fit into the schedule or budget and remove the technology from demonstration consideration.

This flexible and dynamic technology screening process allows for growth in the selection process as CET's mission evolves and DOE environmental needs change.

\section{REFERENCES}

Center for Environmental Technology. 1994. CET Responds to Environmental Challenges by Linking Technology Users and Providers. Spring Newsletter, Vol. 1, No. 1.

Center for Environmental Technology. Environmental Leadership Through Creative Solutions. S.A. Meacham, CET Director. Informational Brochure.

Center for Environmental Technology. S.A. Meacham, CET Director. Communication on Creative Environmental Solutions. Informational Brochure.

EG\&G. 1993. Final Report for Center for Applied Development of Environmental Technology, Idaho Falls. 
APPENDIX A 


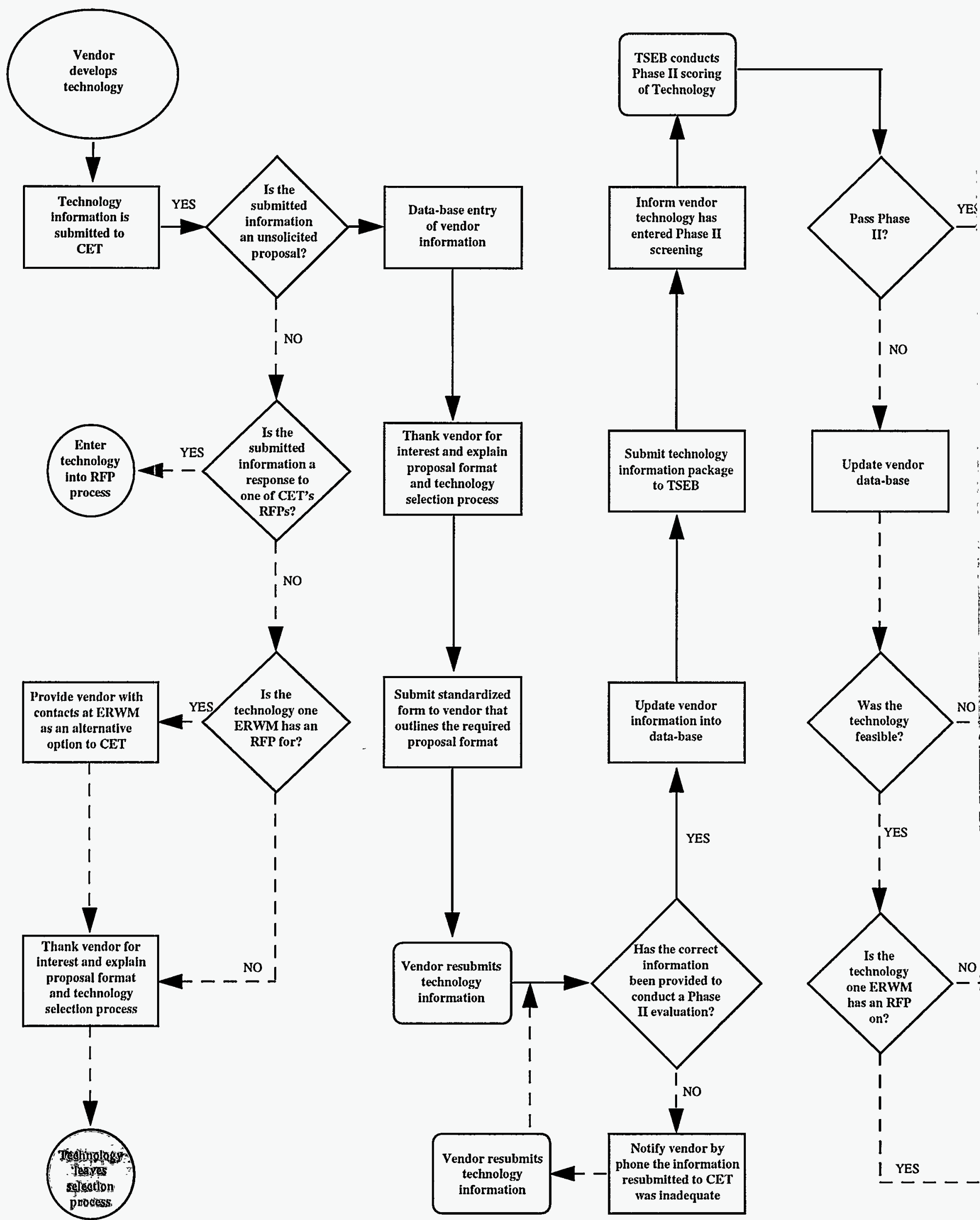


APPENDIX B 


\section{Center for Environmental Technology Innovative Technology Proposal Guidelines}

Instructions: The Center for Environmental Technology has developed a standard proposal format to provide all vendors an equal opportunity to address the criteria against which each technology will be evaluated. Proposals submitted to the Center for Environmental Technology that address information beyond the requirements listed on the attached pages and that do not meet the requirements of the standard format will not be accepted for further evaluation. In the event the proposal is unacceptable, the Center for Environmental Technology will contact the vendor, and the proposal will be returned to the vendor for a rewrite. Proposals will only be entered into the technology screening process and forwarded to the Technology Screening and Evaluation Board when all format requirements have been met. Vendors will receive written notification when the proposal has been cleared and the innovative technology has entered into the selection process.

Format: The proposal for each innovative technology is limited to 12 single-spaced, typed pages using 12-point standard font and should address the information described for each section. In addition to the 12 pages of text, 8 pages are allowed for figures, tables, and data as necessary to support the text and must be included as an appendix. Pages in the proposal must be formatted for $81 / 2 \times 11$ standard legal size paper with 1 -in. top and bottom margins and $1 / 2$-in. right and left margins.

Point of Contact: Upon submittal of the proposal, the vendor should supply the Center for Environmental Technology a Point of Contact who can be notified of any questions or information regarding the technology proposal and selection process. Once the Point of Contact has been appointed by the vendor, all future correspondence and communication will be directed to this individual. The Center for Environmental Technology should be notified as soon as possible if the Point of Contact changes. 


\section{PROPOSAL BODY}

\section{Section One: Technical Function}

Information discussed in this section should include a description of the proposed innovative technology's technical function. This section is designed to focus upon "how" the technology operates and "what" it is designed for, i.e., specific scientific and engineering principles. Some topics a vendor could discuss are how contaminants are removed from the media, what contaminants or situations it is specific for, etc.

\section{Section Two: Technical Capabilities}

The objective of this section is for the vendor to discuss the technical abilities of the innovative technology. The vendor could include information such as the level of contamination removed, pollution prevented, safety level achieved, etc. This section should not be confused with Section One which is reserved for "how" the technology works. Rather, Section Two must discuss the objectives of the technology and the output created.

\section{Section Three: Operational Requirements}

The vendor must discuss the operational parts of the technology, materials the technology is composed of, and any special operational requirements the technology may have. The vendor should also discuss the type of training, if any, required for personnel using the equipment.

\section{Section Four: System Requirements}

Information pertaining to any supporting equipment necessary to facilitate the technology's operation must be discussed in this section. An example may be any pumps, utility requirements, holding stations, or other components comprising the technology's working system.

\section{Section Five: Developmental Stage}

The vendor should address where the technology is in terms of developmental stages: theoretical, labscale, bench-scale, pilot-scale, or full-scale. This discussion should include any tests or demonstrations already performed that validate the technology's capabilities.

\section{Section Six: Time Commitment}

The vendor must produce a time estimate, when applicable, as to the duration required for the technology to complete its objectives. If this time frame is dependent on the amount of contamination, type of contamination, and/or size of the site, the vendor should display tables that will give an approximate range on variations of these variables.

\section{Section Seven: Cost Estimate}

The vendor must include in this section the cost estimate and the cost model the estimate was derived from for purchasing the technology, operating the technology, and the maintenance required on the technology.

\section{Section Eight: Cost Sharing}

The vendor should indicate to the Center for Environmental Technology its willingness to fund any of the costs should the technology be chosen for a demonstration. Vendors should also indicate at what level they would be willing to contribute. Although this information is not a commitment, it should be as accurate as possible because it is important for scheduling the demonstrations once technologies are selected. 